\title{
A remote sensing-guided forest inventory concept using multispectral 3D and height information from ZiYuan-3 satellite data
}

\author{
Adelheid Wallner ${ }^{1, *}$, Stefan Friedrich ${ }^{1}$, Emanuel Geier ${ }^{1}$, Christoph Meder-Hokamp ${ }^{1}$, Zillin Wei ${ }^{1}$, Mengistie Kindu ${ }^{1}$, \\ Jiaojiao Tian ${ }^{2}$, Martin Döllerer ${ }^{1}$, Thomas Schneider ${ }^{1}$ and Thomas Knoke ${ }^{1}$ \\ ${ }^{1}$ Institute of Forest Management, TUM School of Life Sciences Weihenstephan, Technical University of Munich (TUM), D-85354 Freising, \\ Germany \\ ${ }^{2}$ Remote Sensing Technology Institute (IMF), German Aerospace Center (DLR), Oberpfaffenhofen, D-82234 Wessling, Germany
}

*Corresponding author: E-mail: adelheid.wallner@tum.de

Received 20 April 2021

\begin{abstract}
Increased frequencies of storms and droughts due to climate change are changing central European forests more rapidly than in previous decades. To monitor these changes, multispectral 3D remote sensing (RS) data can provide relevant information for forest management and inventory. In this case study, data of the multispectral 3D-capable satellite system ZiYuan-3 (ZY-3) were used in a RS-guided forest inventory concept to reduce the field sample size compared to the standard grid inventory. We first pre-stratified the forest area via the ZY-3 dataset into coniferous, broadleaved and mixed forest types using object-based image analysis. Each forest type was then split into three height strata using the ZY-3 stereo module-derived digital canopy height model (CHM). Due to limited sample sizes, we reduced the nine to six strata. Then, for each of the six strata, we randomly selected representative segments for inventory plot placement. We then conducted field inventories in these plots. The collected field data were used to calculate forest attributes, such as tree species composition, timber volume and canopy height at plot level (terrestrially measured tree height and height information from ZY-3 $\mathrm{CHM}$ ). Subsequently, we compared the resulting forest attributes from the RS-guided inventory with the reference data from a grid inventory based only on field plots. The difference in mean timber volumes to the reference was $+30.21 \mathrm{~m}^{3} \mathrm{ha}^{-1}$ (8.99 per cent) for the RS-guided inventory with terrestrial height and $-11.32 \mathrm{~m}^{3} \mathrm{ha}^{-1}(-3.37$ per cent) with height information from ZY-3 data. The relative efficiency (RE) indicator was used to compare the different sampling schemes. The RE as compared to a random reduction of the sample size was 1.22 for the RS-guided inventory with terrestrial height measurements and 1.85 with height information from ZY-3 data. The results show that the presented workflow based on 3D ZY-3 data is suitable to support forest inventories by reducing the sample size and hence potentially increase the inventory frequency.
\end{abstract}

\section{Introduction}

Forest inventories provide essential information on tree resources and forest structure for planning and management. In Germany, forest inventories on a regional and national scale are usually performed at intervals of 10-20 years. However, due to climate change, the frequency and magnitude of biotic and abiotic calamities has increased (IPCC 2018). This increase requires a shortening of previous inventory intervals to detect forest changes and adapt management strategies accordingly. Switzerland, for example, has turned from a periodic to an annual inventory concept for the Swiss National Forest Inventory (NFI) in 2009 (Massey et al. 2014). However, the drawback of the annual concept is a loss in precision due to the reduced number of permanent terrestrial plots that can be inventoried within a year. To address this precision loss, Massey et al. (2014) suggested the integration of aerial remote sensing (RS) data in a three-phase regression estimation technique in combination with past inventory data. This approach enables more flexibility for forest-related data taken from permanent grid sampling plots and manually interpreted aerial RS data, as well as the implementation of variance reduction tools, such as poststratification. In Switzerland, an improved sampling technique for the Swiss NFI was also tested for nationwide use of a canopy height model (CHM) based on aerial images (Ginzler and Hobi 2015). The CHM was used as auxiliary information to poststratify the forest area and to reduce estimation errors. The two studies from Switzerland for the NFI have shown that very high-resolution aerial images have great potential for optimizing inventory concepts.

The optimization of inventory concepts using other RS data types has also been examined in numerous studies. Köhl et al. (2006) describe different approaches to optimize sampling concepts using auxiliary information from RS data. Auxiliary information can be used after sampling to apply post-stratification to

(c) The Author(s) 2021. Published by Oxford University Press on behalf of Institute of Chartered Foresters. All rights reserved. For permissions, please e-mail: journals.permissions@oup.com. 
the sample plots by aggregating them into homogenous units. Pulkkinen et al. (2018) applied post-stratified estimation in two real NFI estimation cycles based on stereo aerial images and reduced the variance of forest inventory characteristics, such as growing-stock volume. Prior to sampling, a stratification of the population can be performed with auxiliary information. By stratifying the forest into homogeneous subpopulations, the variance is reduced compared to simple random sampling (SRS). Thus, a lower number of sample plots may suffice to achieve a targeted precision. Grafström et al. (2014) and Wallner et al. (2018) provide examples of this approach. Further, the approach of twophase sampling can be used to support terrestrial sampling in combination with wall-to-wall maps, which are generated with observations from auxiliary data correlated to the response variable, such as growing-stock volume. Tomppo (2006) showed the use of two-phase sampling in the frame of the Finnish multisource NFI. They used satellite and digital map data as auxiliary information in addition to field data to produce estimates for small areas and wall-to-wall maps. Gautam et al. (2010) applied a related approach for estimating aboveground biomass in a tropical forest. In the first phase, they used the satellite characteristics of Advanced Land Observation Satellite (ALOS) and Landsat 7 data to produce a wall-to-wall map of categories, such as forest, non-forest and uncertain areas. In the second-phase, they performed an optimized field data collection and collected a sample of light detection and ranging (LiDAR) transects over the target area. Hawbaker et al. (2009) compared stratified sampling with random sampling using LiDAR data as auxiliary information and modelled forest structural information, such as diameter at breast height (DBH), basal area, tree height and biomass. The mentioned studies showed that auxiliary data sources have a high potential to support forest sampling concepts. LiDAR and aerial data provide structural information, but they are comparably costly and limited in area coverage. Satellite data such as ALOS and Landsat 7 provide high-area coverage free of cost but have limited information on forest structure. An alternative can be data from high-resolution RS systems with the ability of stereo imaging, which enables the derivation of $\mathrm{CHM}$.

Several satellite systems have appropriate sensors to collect data to generate CHM from high-resolution stereo imagery. The common stereo systems use along-track stereoscopy, which captures two or more views from the same orbit. Studies using high-resolution stereo imagery for forest applications in Germany include SPOT-5, GeoEye-1/2, WorldView2/3, ALOS/PRISM, CHRIS/Proba and Cartosat-1 (Schneider 2009; Buchhorn and Schneider 2010a, 2010b; Tian 2013a; Straub et al. 2013; Immitzer et al. 2016; Fassnacht et al. 2017; Tian et al. 2017). Straub et al. (2013) assessed the usefulness of stereoscopic satellite data from Cartosat-1 and WorldView-2 stereo imagery for forestry applications by modelling timber volume. Additionally, forest monitoring and change detection of forest coverage were analysed with stereoscopic satellite data by Tian et al. (2013b) and Tian et al. (2017) using data of WorldView-2, IKONOS, Cartosat-1, ALOS/PRISM and RapidEye. Further, Immitzer et al. (2016) generated wall-to-wall maps of timber volume with height values from WorldView-2 data in conjunction with German NFI data. To date, most of the studies used 3D satellite data to support forest management based on forest attribute estimation, forest monitoring and change detection analysis. However, 3D satellite data have so far not been used for optimizing the sampling concept of forest inventories over heterogeneous forests in Germany.

Studies based on the Chinese multispectral (MS) stereoscopic satellite system ZiYuan-3 (ZY-3) have shown that these data offer great potential for supporting forest management and inventories. In the study of Li et al. (2019), stand height was tested for forest mapping. Additionally, Xie et al. (2019) added CHM data in a land use and land cover (LULC) classification into different land-cover types, forest types and tree species. Moreover, Li et al. (2019) estimated aboveground biomass of a larch plantation in China using MS-3D ZY-3 data.

The main objective of the current study was to assess the performance of a RS-guided inventory concept, based on information derived from ZY-3 MS and three-line stereo data. The key question was whether the combined spectral-structural information derived from ZY-3 data is accurate enough to increase the efficiency of forest inventory processes via a pre-stratification of the forest stands. If successful, pre-stratification offers the possibility to reduce the number of inventory plots by homogenizing the study area without a loss of precision. In German forest management planning, a threshold $<5$ per cent relative standard error is recommended for the estimation of timber volume at stand- and aggregated enterprise-level (Knoke et al. 2012). With this in mind, the following research questions were addressed:

1. Does the pre-stratification of forest stands using MS-3D satellite data permit the reduction of inventory plots while keeping the standard error below the desired threshold of 5 per cent?

2. How well does the RS-guided inventory perform compared to the grid inventory with respect to the forest attributes 'height at plot level', 'tree species composition' and 'timber volume'?

\section{Study site}

The study site is located $5 \mathrm{~km}$ north of the city Landshut (Figure 1) in eastern Bavaria, Germany. The university forest is part of a forest owned by the Ludwig Maximilian University of Munich. The study site covers an area of 349 ha and belongs to the forest ecoregion 'Western Lower Bavarian Tertiary Hilly-Country' (12.9/1) (Walentowski et al. 2001). As described in Müller-Starck et al. (2019), the natural forest vegetation is classified as Fagus-Abies forest zone. During the vegetation period, the temperature at the site is higher $\left(15.7^{\circ} \mathrm{C}\right)$ and the precipitation is lower $(280 \mathrm{~mm})$ than the Bavarian mean values $\left(7.8^{\circ} \mathrm{C}\right.$ and $\left.700 \mathrm{~mm}\right)$. The elevation ranges between $440 \mathrm{~m}$ to $550 \mathrm{~m}$ above sea level (Mosandl and Höllerl 2013).

Norway spruce (Picea abies (L.) H. Karsten) is the most frequent tree species across every age group. In order to achieve forest conversion from homogeneous to heterogeneous mixed stands, a change in the management strategy for spruce was undertaken. The forest conversion led to a decline of spruce from 59 per cent in 2002 to 46 per cent in 2016 (Friedrich et al. 2017, Müller-Starck et al. 2019). This in turn lead to an increase in the tree species European beech (Fagus sylvatica L.), common oak (Quercus robur L.), silver fir (Abies Alba Mill.), pine (Pinus sylvestris L.), larch (Larix Mill.) and Douglas fir (Pseudotsuga menziesii). Due to the change in management strategy, various hardwoods also benefited. The high-quality valuable hardwoods, referred to as 

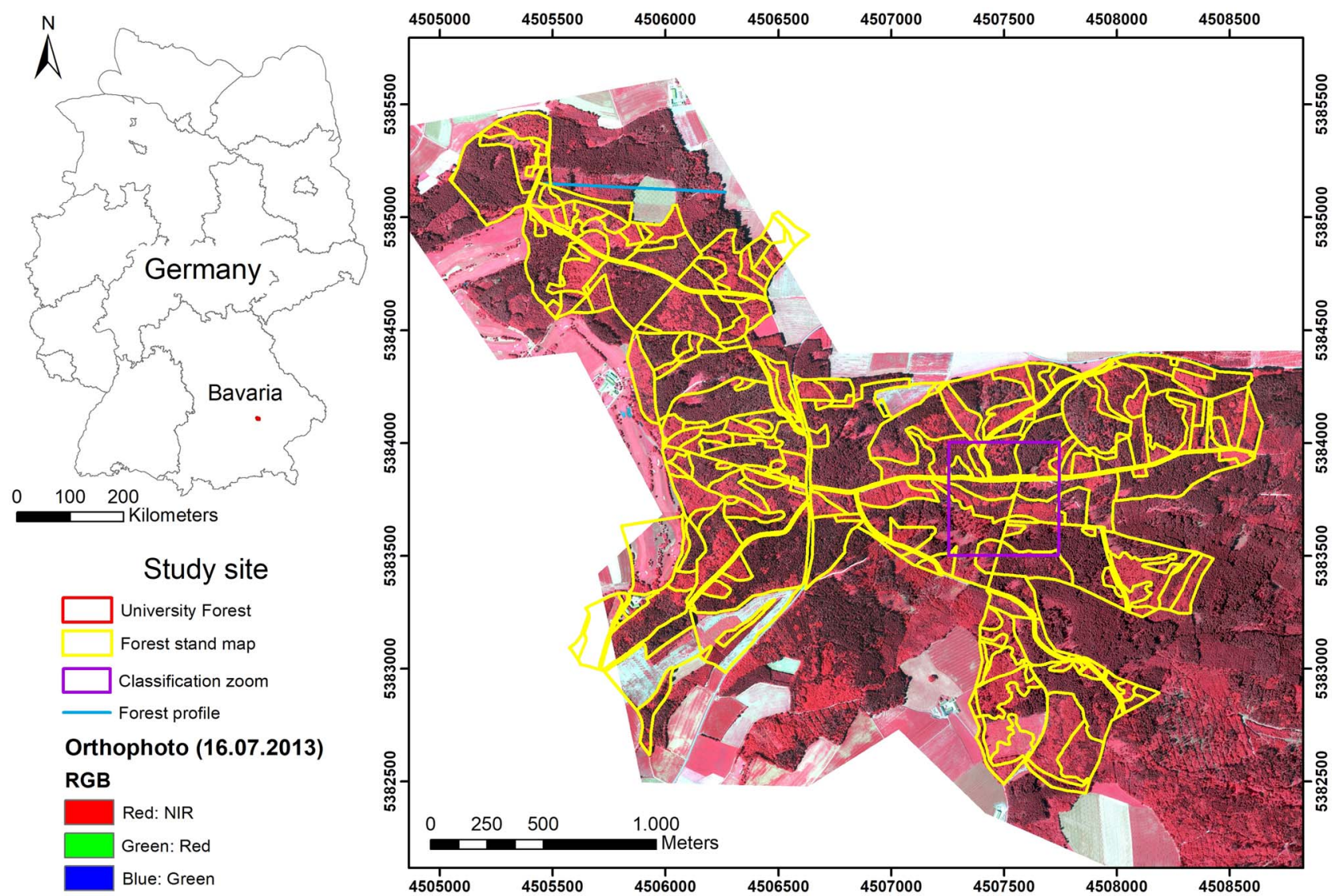

Figure 1 Location of the study site in Bavaria, Germany (top left). The picture on the right shows an orthophoto (Geobasisdaten: Bayerische Vermessungsverwaltung). The forest stand divisions, the position of the forest profile and cross-section (Figure 3 ) and the subset with the enlargement of the classification result (Figure 4) are highlighted.

precious hardwoods in this study, include the mountain maple (Acer spicatum Lam.), ash (Fraxinus L.), wild cherry (Prunus avium L.) and elm (Ulmus L.). Other hardwoods in the study include birch (Betula L.), European aspen (Populus tremula L.), rowanberry (Sorbus aucuparia L.), hornbeam (Carpinus L.) and poplar (Populus L.). The forest conversion led to a variety of stand type structures, which range from even-aged spruce monocultures to unevenaged mixed stands (Knoke and Weber 2006; Mosandl and Höllerl 2013, Müller-Starck et al. 2019).

\section{Materials}

\section{ZY-3 satellite data}

Our study is based on a dataset of the Chinese ZY-3 satellite system captured on 09 September 2012. The ZY-3 earth observation system was developed and launched in January 2012 by the Satellite Surveying and Mapping Application Centre of the National Administration of Surveying Mapping and Geoinformation of China (Fang and Chen 2012). The system combines a three-line stereo and a four-band MS imaging module at 11-bit radiometric resolution. The stereo module consists of two $22^{\circ}$ forward- and backward-looking sensors with $3.5 \mathrm{~m}$ resolution and a nadir-looking sensor of $2.1 \mathrm{~m}$ resolution. The
MS module combines four spectral bands with $5.8 \mathrm{~m}$ resolution covering the blue (450-520 nm), green (520-590 nm), red (630$690 \mathrm{~nm})$ and near infrared (NIR) $(770-890 \mathrm{~nm})$ spectral ranges (Tang and Xie 2012).

\section{Reference data}

Our reference and validation dataset is composed of two data sources: (1) inventory field data from the permanent grid inventory of the university forest, and (2) LiDAR data and digital orthophotos from the Bavarian Agency for Digitisation, HighSpeed Internet and Surveying (Landesamt für Digitalisierung, Breitband und Vermessung, LDBV).

\section{Permanent grid inventory}

The permanent grid inventory is carried out in the university forest in a cycle of about 10 years. The inventory is based on concentric sample plots in a fine-resolution grid of $100 \mathrm{~m} \times 100 \mathrm{~m}$. Measurements are regularly taken on 348 permanently marked field plots. The centre of the inventory circle was marked with a buried magnet during the initial recording of the data at the inventory point. The last permanent inventory was carried out in 2002. In 2012, there was an unexpected change in management and 
the follow-up inventory was postponed until 2016. The criteria for data collection were based on three concentric circular plots (Knoke et al. 2012). The main variables recorded at the plots were $\mathrm{DBH}$, age, tree species, tree position coordinates and tree height. Tree age was either updated from the previous permanent inventory (2002) or estimated by the inventory staff based on growth rings counted at the stumps of recently harvested trees with similar DBH values. Tree heights were updated for the same trees measured in the previous inventory. Additional tree heights were field-sampled from trees in the upper end of the DBH range. For trees without field-height measurements, we used diameter-age regression models by Johann (1990).

\section{LiDAR data and digital orthophotos}

We used LiDAR data and digital orthophotos provided by the LDBV. The LiDAR datasets were collected in March 2011 and April 2013 as first and last pulse echoes with a point density of 4 points $/ \mathrm{m}^{2}$. From the LiDAR data, a digital terrain model (DTM) and a digital surface model (DSM) were calculated. The models were prepared with the software ArcGIS 10.4 with a spatial resolution of $1 \mathrm{~m}$. To compare the datasets at pixel level, the LiDAR DTM and LiDAR DSM were resampled to $5 \mathrm{~m}$ resolution to have the same spatial resolution as the ZY-3 DSM. A LiDAR CHM was calculated as the difference between LiDAR DSM and LiDAR DTM.

The digital orthophoto was derived from aerial images that were recorded on 16 July 2013 using a Vexcel UltraCam-XP camera during the regular aerial survey of Bavaria. The product was delivered at $0.2 \mathrm{~m}$ spatial resolution and provided as a four-band spectral dataset (blue, green, red and NIR).

\section{Methods}

The main methodological steps are summarized in Figure 2.

\section{Generation of ZY-3 height models}

For DSM generation, we used the image processing software DLR$x$ Dibias. The latter is a peer research software with the latest image processing techniques developed at DLR (Han et al. 2020). The DSM was generated from the ZY-3 data using the semiglobal matching (SGM) algorithm in combination with two wellknown similarity measurements (census and mutual information), which are selected in the standard SGM stereo matching procedure (Hirschmüller 2008, d'Angelo et al. 2008). Following the method in d'Angelo (2013), a ZY-3 DSM with $5 \mathrm{~m}$ spatial resolution was generated based on the combination of NadirBackward, Nadir-Forward and Backward-Forward image pairs. The ZY-3 DSM was co-registered to the LiDAR DSM based on a 3D co-registration procedure (Straub et al. 2013). The steps of the DSM generation procedure are described in detail in Tian et al. (2013b). Finally, the ZY-3 CHM was derived by subtracting the LiDAR DTM.

An accuracy assessment was carried out for the DSM and CHM in terms of vertical offset. Two different reference datasets were used: (1) the LiDAR DSM and (2) canopy height at plot level acquired during the terrestrial measurements. First, ZY-3 DSM was visually compared with the LiDAR DSM. Second, for quantifying the deviance in elevation, the difference between ZY-3 DSM and LiDAR DSM was calculated based on a statistically validated number of samples collected as pixel values and distributed over the study site. The samples represent different land-cover types such as sealed surface, high-density coniferous forest, low-density coniferous forest, deciduous forest and grassland. As robust accuracy measures the mean error (ME), requiring the computation of standard deviation (STD), the normalized median absolute deviation (NMAD), and the root mean square error (RMSE) were calculated. The STD, NMAD and the RMSE of the whole sample size and the sample size without outliers (threshold for outlier exclusion $\pm 3 \times$ RMSE) were calculated according to Höhle and Höhle (2009) and Höhle and Potuckova (2011). We additionally compared the ZY-3 DSM and LiDAR DSM using a cross-section through a highly structured forest section (Figure 1). For all pixels along the cross-section we calculated the mean absolute error (MAE), the ME and RMSE.

\section{ZY-3 data processing and analysis}

The pre-processing step of geometric rectification was performed on the ZY-3 dataset using PCI Geomatica V software. The segmentation and classification of the image data was performed with the software package eCognition 9.0 and 9.1 by Trimble Geospatial (Baatz et al. 2004) using an object-based image analysis (OBIA) technique (deKok et al. 1999; Blaschke 2010). The OBIA technique explored height and angular information from stereo-bands combined with spectral information from the MS bands as described in Wei (2018). Angular signatures, which provide information on the anisotropy behaviour of the surfaces, were derived via the ratio of the forward (st1) and backward (st2) stereo band reflectance (anisotropy ratio, AR). The classification entailed a top-down concept within a three-level hierarchical process, based on forest level, stand level and pixel level. For classification, the membership function approach offered by eCognition was used, which works with user-defined functions of the image object features (Baatz et al. 2004). For each level, a rule set was developed based on the class properties. The discriminating features on each level were either the digital number of the respective bands ('color' in eCognition nomenclature), AR, normalized different vegetation index (Rouse et al. 1974) or the ZY-3 CHM.

The forest area was discriminated from other land-cover types by applying a multiresolution segmentation with scale (50), shape (0.1) and compactness (0.5) on the hierarchical process level forest. The classification on forest level was performed with a membership function using the ratio Brightness visible, which is based on the ratio Brightness from the Trimble Reference Book (2013).

On the pixel level, a chessboard segmentation algorithm was used to receive pixel-size objects of $5 \mathrm{~m} \times 5 \mathrm{~m}$. The objects were classified with a membership function into coniferous, broadleaved and others (grass and no vegetation). The classification result at pixel level was verified by visual interpretation based on digital CIR orthophotos. For the validation, a sample size per class with the ratio 6:2:1 (coniferous, broadleaved and others) was chosen based on the tree species composition of the forest. In total, 400 samples were visually interpreted in the CIR orthophotos. The accuracy assessment was conducted by 


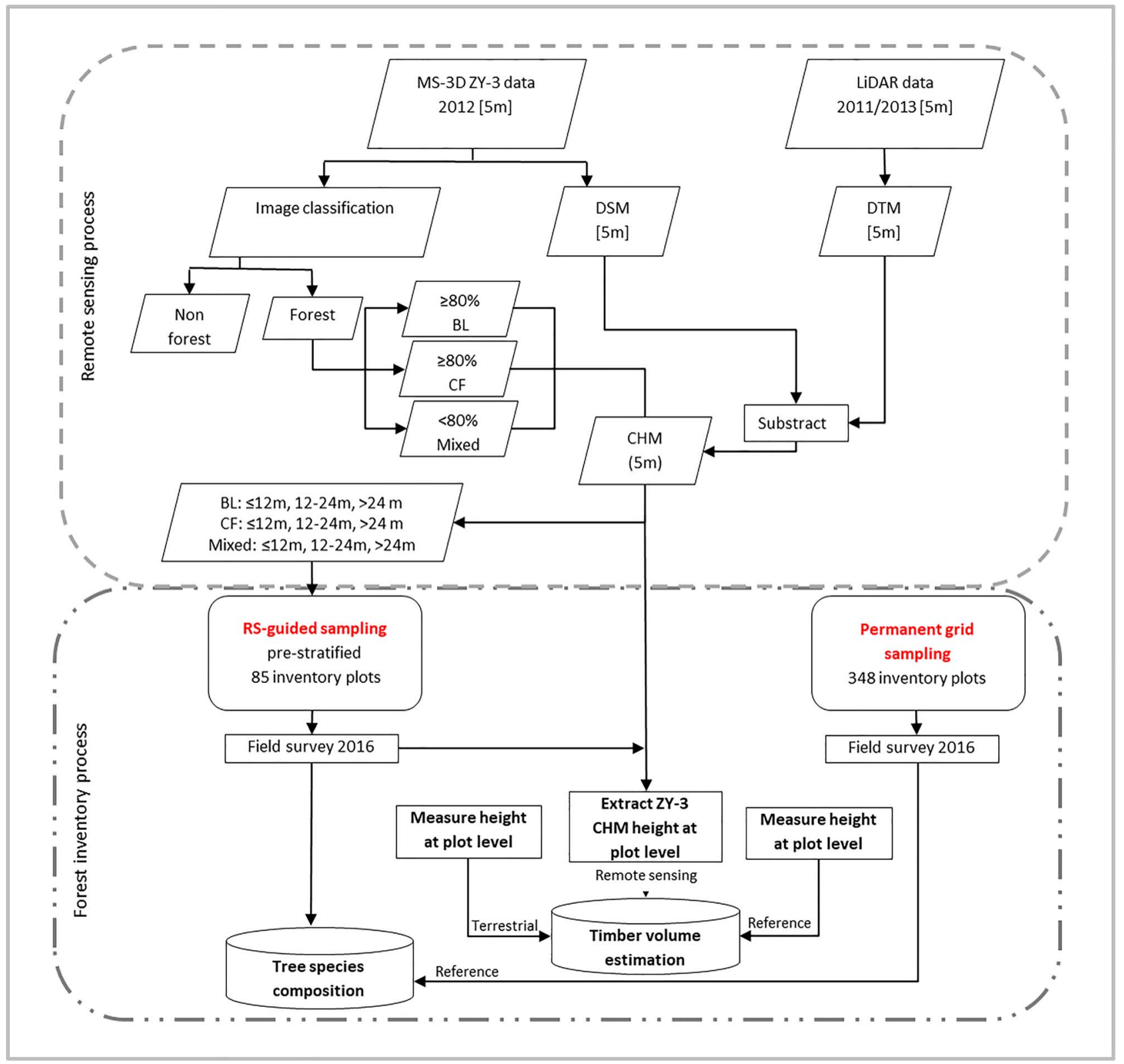

Figure 2 Methodological workflow of the RS-guided sampling and grid sampling concept.

creating an error matrix that included the overall accuracy $(O A)$, producer accuracy (PA) and user accuracy (UA). Furthermore, Kappa was calculated (Congalton 1991).

On stand level, a multiresolution segmentation algorithm was carried out with a scale factor of 12 , shape of 0.1 and compactness of 0.5 . The resulting objects were assigned to the classes: pure coniferous, pure broadleaved and mixed stands. The share of objects at pixel level was $\geq 80$ per cent for pure coniferous and broadleaved stands. In the final classification step, we used the mean object height at stand level to assign the existing objects into three additional height classes, resulting in nine final classes or strata. As a threshold, we used typical heights associated with the development stages: $\leq 12 \mathrm{~m}$ (establishment), 12-24 m (stabilization/qualification) and $>24 \mathrm{~m}$ (dimensioning) (Mosandl and Paulus 2002; Knoke et al. 2012).

\section{RS-guided inventory concept based on ZY-3 data}

The classification result at stand level was used to conduct a pre-stratified sampling within a RS-guided inventory concept. The number of the standard grid inventory plots (348 sample plots) results from a very fine grid of inventory plots in the format $100 \mathrm{~m} \times 100 \mathrm{~m}$, that is, one plot per hectare. We reduced the number of inventory plots for the pre-stratified RS-guided sampling design by about 75 per cent (to 85 plots) to match the same number of plots per hectare as the inventory design of the 
Table 1 Overview of strata area, number of inventory plots and weights of inventory plots and strata.

\begin{tabular}{lllll}
\hline & $N_{\mathrm{h}}[\mathrm{ha}]$ & $n_{\mathrm{h}}$ & $w_{\mathrm{h}}$ & $W_{\mathrm{h}}$ \\
\hline $\mathrm{BL}$ 0-12 m & 25 & 5 & $6 \%$ & $7 \%$ \\
$\mathrm{BL}>12 \mathrm{~m}$ & 42 & 17 & $20 \%$ & $12 \%$ \\
CF $0-12 \mathrm{~m}$ & 47 & 8 & $9 \%$ & $14 \%$ \\
CF $>12-24 \mathrm{~m}$ & 158 & 36 & $42 \%$ & $45 \%$ \\
CF $>24 \mathrm{~m}$ & 35 & 10 & $12 \%$ & $10 \%$ \\
Mixed & 42 & 9 & $11 \%$ & $12 \%$ \\
Total & 349 & 85 & $100 \%$ & $100 \%$ \\
\end{tabular}

Note: $N_{h}=$ stratum area; $n_{h}=$ sample size of the stratum $h ; w_{h}=$ sample size weights; $W_{h}=$ stratum weights; $B L=$ broadleaved; $C F=$ coniferous.

Bavarian State Forest agency (BaySF) which uses a $200 \mathrm{~m} \times 200 \mathrm{~m}$ grid. Our pre-stratification revealed from a statistical point of view, that we could not evaluate the area of some strata in relation to the necessary number of samples. Therefore, we summarized the mixed classes as mixed forest type without height stratification. Furthermore, we combined and categorized the strata broadleaved $>12-24 \mathrm{~m}$ and broadleaved $>24 \mathrm{~m}$ as broadleaved $>12 \mathrm{~m}$ (Table 1 ). For the spatial allocation of the RS-guided sampling plots, we used the automatically calculated centre of gravity of the OBIA classification (Baatz et al. 2004). Based on the OBIA classification, objects were considered as stratum candidates if they were large enough to completely include an inventory plot $\left(500 \mathrm{~m}^{2}\right)$. From those candidates, the final 85 segments for inventory plot allocation were randomly selected in ArcGIS 10.4. Subsequently, we identified the locations of these plots with a GPS and inventoried the plots in the field, following the scheme described in the subsection reference data of the materials section. The tree height was measured at each inventory plot for the two thickest trees per species.

\section{Comparison of RS-guided inventory with permanent grid inventory}

The RS-guided forest inventory was compared with the permanent grid inventory based on the forest attributes canopy height at plot level (terrestrially measured tree height and height information from ZY-3 data), tree species composition and timber volume.

Comparison of canopy height at plot level from different datasets We compared height information at inventory plot level from RS-guided sampling based on ZY-3 CHM data with terrestrial measured tree height. We used the tool 'zonal statistic' within the software package ArcGIS 10.4 to calculate different height metrics from the $\mathrm{ZY}-3 \mathrm{CHM}$ data at the inventory plot locations. For the canopy height analysis, we found the maximum height metric suitable, representing the top height at the inventory plot level. In our study, a time gap occurred between the RS data acquired in 2012 and the terrestrial measurements recorded in 2016. The periodic annual increment (PAI) was calculated with data taken from the grid inventory plots as recorded for the 2002 and 2016 inventories. We calculated the PAI of each tree species based on a certain number of trees $(n)$ measured at the grid inventory plots (Table 2) and received a tree speciesspecific PAI representing the annual mean increment of tree species including all age classes. An overall PAI of 4 years was added to the maximum height values derived from the $\mathrm{ZY}-3 \mathrm{CHM}$ pixel values at plot level and compared with maximum values of terrestrial measurements at plot level of the RS-guided sampling design.

\section{Tree species composition}

The share of tree species composition was calculated based on the field data collected through the RS-guided inventory and grid inventory according to Dahm (2006, p. 14). The tree species composition of spruce, silver fir, Douglas fir, pine, larch, beech, oak, precious hardwoods and other hardwoods of the RS-guided inventory was statistically compared to the grid inventory. To rule out differences in tree species composition of both datasets, the statistical similarity of variances was evaluated by an F-test and the similarity of the mean by a $t$ test. For both methods, we used a significance threshold of $P=0.05$.

\section{Timber volume estimation}

We estimated the volume of single trees with bark via allometric models based on height, DBH and form-height functions (Kennel 1973). The timber volume (in cubic metres per hectare of timber harvested without bark) at plot level was calculated based on the volume values of single trees. The height of trees with missing field-recorded heights was calculated with the diameterage regression model from equation (1) developed by Johann (1990). The diameter-age regression model based on tree species or groups of tree species was parameterized with field-recorded tree heights ( $n=336$ trees).

$$
\text { Height }=\text { Intercept }+\mathrm{a} * \ln \mathrm{DBH}+\mathrm{b} * \ln \mathrm{DBH} * \text { Age }
$$

The main difference between the described forest inventories is the sample design. Therefore, we analysed the RS-guided sampling according to formulas for stratified random sampling (Str) Cochran (1977). The stratum weights $W_{h}$ were defined as a proportion of each stratum size in relation to the total population area $\left(\mathrm{W}_{\mathrm{h}}=\frac{N_{\mathrm{h}}}{\mathrm{N}}\right)$, where $N_{\mathrm{h}}$ is the size of stratum $h$ with $L$ strata, and $N$ is the population size $\left(N=\sum_{h=1}^{L} N_{h}\right)$. The standard error of the stratified population mean $\mathrm{S}_{\bar{y}_{\text {str }}}$ from equation (2) was 
Table 2 PAI of height calculated from grid inventory data from 2002 and 2016.

\begin{tabular}{lllll}
\hline Tree species & Mean $[\mathrm{m}]$ & Std. $[\mathrm{m}]$ & $N$ & Std. Error $[\mathrm{m}]$ \\
\hline Douglas fir & 0.60 & 0.23 & 24 & 0.046 \\
Larch & 0.37 & 0.25 & 97 & 0.028 \\
Pine & 0.33 & 0.20 & 28 & 0.021 \\
Silver fir & 0.33 & 0.20 & 156 & 0.037 \\
Spruce & 0.35 & 0.20 & 39 & 0.016 \\
Precious hardwoods & 0.48 & 0.28 & 40 & 0.044 \\
Other hardwoods & 0.40 & 0.22 & 92 & 0.034 \\
Oak & 0.46 & 0.26 & 74 & 0.027 \\
Beech & 0.51 & 0.32 & & 0.037 \\
\hline
\end{tabular}

Note: Std. = standard deviation; $\mathrm{N}=$ number of individuals measured at the permanent inventory plots; Std. Error = standard error.

calculated without using a finite population correction factor because $<5$ per cent of the population was sampled (Cochran 1977, p. 93, equation 5.7).

$$
\mathrm{s}_{\bar{y}_{s t r}}=\sqrt{\sum_{h=1}^{L} \mathrm{~W}_{\mathrm{h}}^{2} * \frac{s_{\mathrm{h}} 2}{\mathrm{n}_{\mathrm{h}}}}
$$

where:

$\mathrm{s}_{\bar{y}_{\text {str }}}=$ standard error of the stratified population mean;

$n_{h}=$ sample size of the stratum $h$;

$\mathrm{W}_{\mathrm{h}}=$ stratum weights;

$s_{h}^{2}=$ variance of the stratum $h$.

The grid sampling based on timber volume was evaluated with formulas for simple random sampling (SRS) by applying equation (3) (Cochran 1977, p. 27, equation 2.22). Shiver and Borders (1996) showed that variance estimators developed for SRS are valid for systematic sampling but lead to conservative estimates of the population variance. However, criticism by Cochran (1977) and Köhl et al. (2006) pointed out that using SRS estimators with systematic sampling could, on average, lead to an overestimation of the actual error. We accepted this potential disadvantage and assumed that the systematic sampling represents a random distribution for the population of this very heterogeneous forest because the starting point of the sampling grid was random. The standard error of the sample mean sy was calculated assuming SRS.

$$
s_{\bar{y}}=\sqrt{\frac{s_{y}^{2}}{n}}
$$

where:

$\mathrm{S}_{\overline{\mathrm{y}}}=$ standard error of the sample mean;

$\mathrm{s}_{\mathrm{y}}^{2}=$ variance;

$n=$ sample size.

The frequency distribution of the estimated timber volume of both sampling schemes was visually analysed and statistically evaluated by a chi-square test. We also applied a Monte Carlo Simulation (MCS) to the grid sampling scheme to verify the performance of the RS-guided sampling concept. For this, the range of estimated timber volume of the grid sampling data with a reduced sample size was determined using MCS. The reduction of grid sampling was repeated 1000 times by a random selection of 85 sample plots from the 348 sample plots. The reduced sample size corresponds to the $200 \mathrm{~m}$ grid of the BaySF inventory concept (one plot per 4 hectares).

Furthermore, we conducted a variance analysis based on the relative efficiency (RE) to quantify the efficiency of the different sampling methods by use of equation (4). The ratio of RE compares the estimated variance of the sampling mean of different designs whereby $n$ must be constant (McRoberts et al. 2002). In our case, we compared the estimated mean variance of the MCS with the estimated mean variance of 'RS-guided sampling' with three and six strata, as well as with maximum height information at plot level from ZY-3 CHM data called 'RS-guided sampling with CHM-height'.

$$
\mathrm{RE}=\frac{\mathrm{s}_{\overline{\mathrm{y}}}^{2}}{\mathrm{~s}_{\overline{\mathrm{y}}_{\mathrm{str}}}^{2}},
$$

where:

$\mathrm{s}_{\mathrm{y}}^{2}=$ variance of the estimated population mean of SRS;

$\mathrm{s}_{\overline{\mathrm{y}}_{\mathrm{str}}}^{2}=$ variance of the estimated population mean of Str.

We used the methods described above to analyse the refinement of the $Z Y-3$ stratification approach in the study site. The estimated stratified timber volume from three strata (coniferous, broadleaved and mixed) was compared to six strata (expanded by height information from $\mathrm{ZY}-3 \mathrm{CHM}$ ) with regard to means, variances, relative standard errors and RE. Furthermore, we compared the different sampling schemes in relation to mean timber volume, variance and total timber volume. In addition, we tested the replacement of terrestrial height information with RS dataderived heights at plot level. The maximum RS height at plot level was used instead of terrestrial measured height at plot level and statistic values of estimated timber volume at plot level was calculated.

\section{Results}

\section{ZY-3 DSM accuracy}

The vertical accuracy of the ZY-3 DSM was assessed by visual analyses and comparing its deviance in elevation with a LiDAR DSM. As expected, single trees were not detectable, and a 
Table 3 Vertical agreement measurements of ZY-3 DSM and LiDAR DSM per land-cover type. For outlier exclusion, a $3 \times$ RMSE-threshold was applied.

\begin{tabular}{|c|c|c|c|c|c|c|c|c|}
\hline Land cover & $\begin{array}{l}\text { Sample } \\
\text { size }\end{array}$ & $\begin{array}{l}\text { Sample size } \\
\text { no outliers }\end{array}$ & Mean $[m]$ & $\begin{array}{l}\text { Median } \\
{[\mathrm{m}]}\end{array}$ & NMAD $[m]$ & STD $[m]$ & $\operatorname{RMSE}[m]$ & $\begin{array}{l}\text { RMSE no } \\
\text { outliers [m] }\end{array}$ \\
\hline Sealed surface & 214 & 211 & 1.10 & 0.80 & 0.71 & 0.96 & 1.99 & 1.46 \\
\hline Low-density coniferous forest & 467 & 459 & 4.03 & 2.67 & 2.53 & 4.06 & 6.42 & 5.72 \\
\hline Deciduous forest & 177 & 177 & 7.00 & 6.17 & 5.50 & 5.62 & 8.96 & 8.96 \\
\hline Grassland & 698 & 685 & 0.96 & 0.75 & 0.69 & 0.81 & 1.43 & 1.25 \\
\hline
\end{tabular}

Table 4 The error matrix of the accuracy assessment between areas classified as coniferous forest, broadleaved forest and others (grass and no vegetation) using ZY-3 data classification and those identified in the CIR-image interpretation

\begin{tabular}{|c|c|c|c|c|c|c|}
\hline \multirow[b]{2}{*}{ ZY-3 classification } & & \multicolumn{5}{|c|}{ Reference } \\
\hline & & CF & $\mathrm{BL}$ & Others & Total & UA \\
\hline & CF & 221 & 41 & 19 & 281 & 0.79 \\
\hline & Others & 2 & 4 & 34 & 40 & 0.85 \\
\hline & Total & 231 & 114 & 55 & 400 & \\
\hline & PA & 0.96 & 0.61 & 0.62 & & \\
\hline
\end{tabular}

Note: $\mathrm{BL}=$ broadleaved; $\mathrm{CF}=$ coniferous; $\mathrm{PA}=$ Producer accuracy; $\mathrm{UA}=$ User accuracy.

smoothing effect was visible (Figure 3A-D). In general, the canopy surface was consistently represented but there was a systematic height offset in the ZY-3 DSM (MAE $=2.65 \mathrm{~m}$; $\mathrm{RMSE}=3.14 \mathrm{~m} ; \mathrm{ME}=-2.0 \mathrm{~m}$ ) which was accounted for, corrected (Figure 3D, green cross-section) and considered in further analysis. The combination of ZY-3 DSM and LiDAR DSM allowed a quality assessment of height values over five different land-cover types (Table 3). The ZY-3 DSM performed well for the land-cover types, sealed surfaces and grassland (NMAD between $0.69 \mathrm{~m}$ and $0.71 \mathrm{~m}$ and a STD between $0.81 \mathrm{~m}$ and $0.96 \mathrm{~m}$ ). For forested areas, the assessment showed acceptable results (NMAD between $1.29 \mathrm{~m}$ and $5.5 \mathrm{~m}$ and a STD between $1.8 \mathrm{~m}$ and $5.62 \mathrm{~m})$.

\section{Forest type classification}

The confusion matrix for the forest type classification showed an OA of 81 per cent with a Kappa statistic value of 64 per cent (Wei 2018). The class of coniferous showed a more precise result, with a PA of 96 per cent and UA of 79 per cent compared to broadleaved with a PA of 61 per cent and an UA of 87 per cent (Figure 4 and Table 4).

\section{Comparison of RS-guided inventory with standard grid inventory}

Comparison of canopy height at plot level from different datasets

In the study, maximum height information from field-measured trees were compared with maximum height values from ZY-3 $\mathrm{CHM}$ data at plot level. The analysis, including outliers, showed a Pearson's correlation ( $r$ ) of 0.61 (Figure 5). Out of the 85 sample plots, eight showed notable deviances from heights measured in the field.

\section{Tree species composition}

The comparison of tree species composition between standard grid and RS-guided samplings is shown in the pie charts covering all tree species (Figure $6 \mathrm{~A}$ and $\mathrm{B}$ ). Coniferous trees represented a 61 per cent share using the grid sampling dataset and a 53.8 per cent share using the RS-guided sampling dataset. In comparison to grid sampling, the RS-guided sampling statistic showed a lower share for spruce and Douglas fir. The other tree species had no discrepancies with respect to their shares. A F-test and a $t$ test were applied to examine for differences in the tree species composition shares. Spruce showed no significant difference in the variance $(F(1.13)=1.11 ; P=0.07)$ and revealed no significant difference of the mean proportion $(t(2541)=-0.17 ; P=0.86)$. However, the statistical analyses for Douglas fir $(F(2.74)=2.79$; $P=0.047)$ and oak $(F(1.28)=1.79 ; P=0.000006)$ showed significant difference in the variances. The $t$ test for Douglas fir $(t(13)=2.72 ; P=0.02)$ and oak $(t(322)=2.52 ; P=0.01)$ also revealed a significant difference in the mean values. All other tree species showed no significant difference in their mean composition. The RS-guided sampling design in Figure 7 displays the share of tree species divided into six strata. In the broadleaved strata (Figure 7), a small proportion of less than 20 per cent belonged to the coniferous tree species. The stratification of the coniferous strata generally showed a dominance of spruce. However, for the stratum coniferous $>24 \mathrm{~m}$, there was also a bigger proportion of silver fir. The mixed stratum represented all tree species besides silver fir. In this stratum, the broadleaved species showed a higher share than coniferous species. 

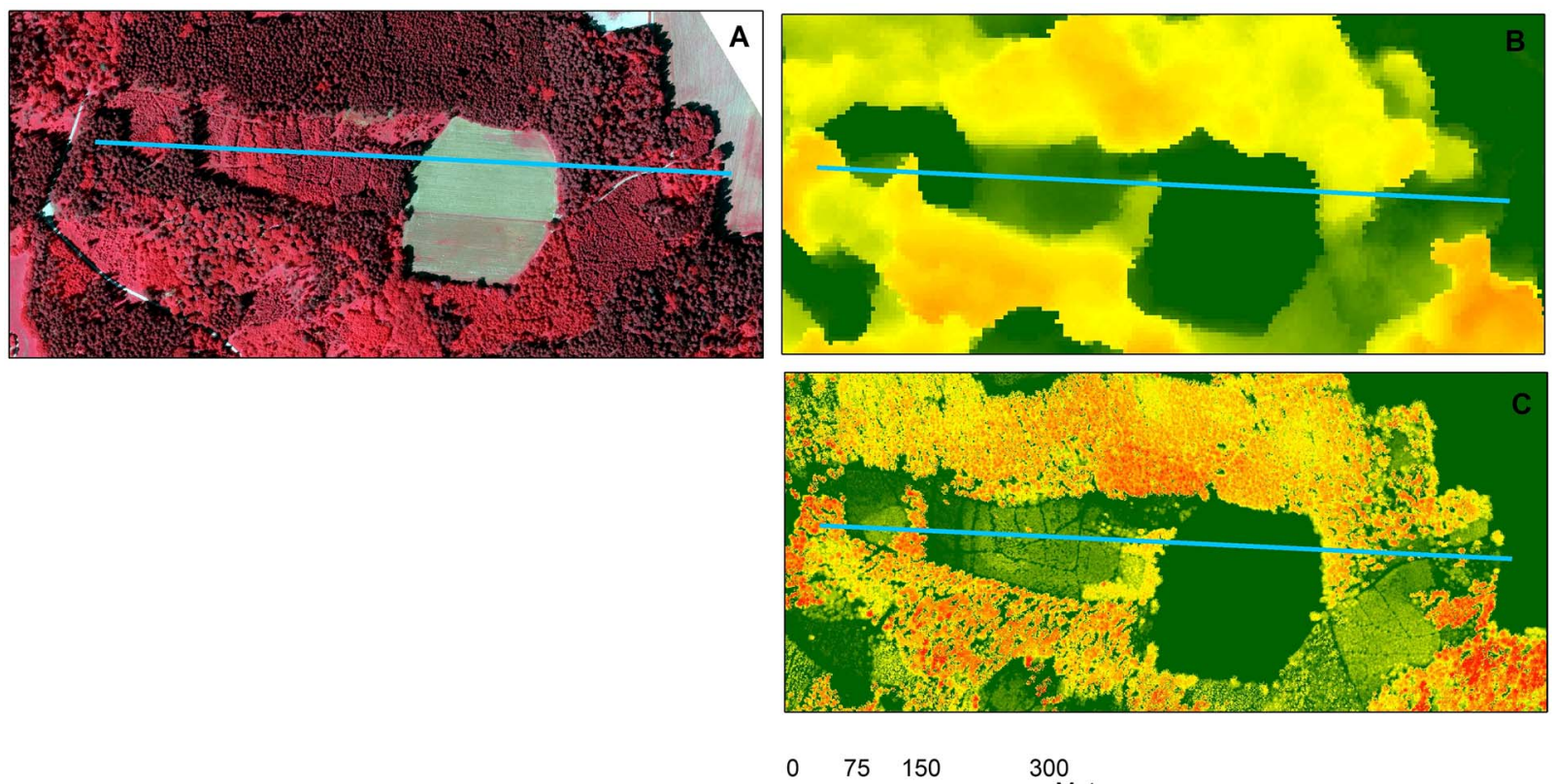

D

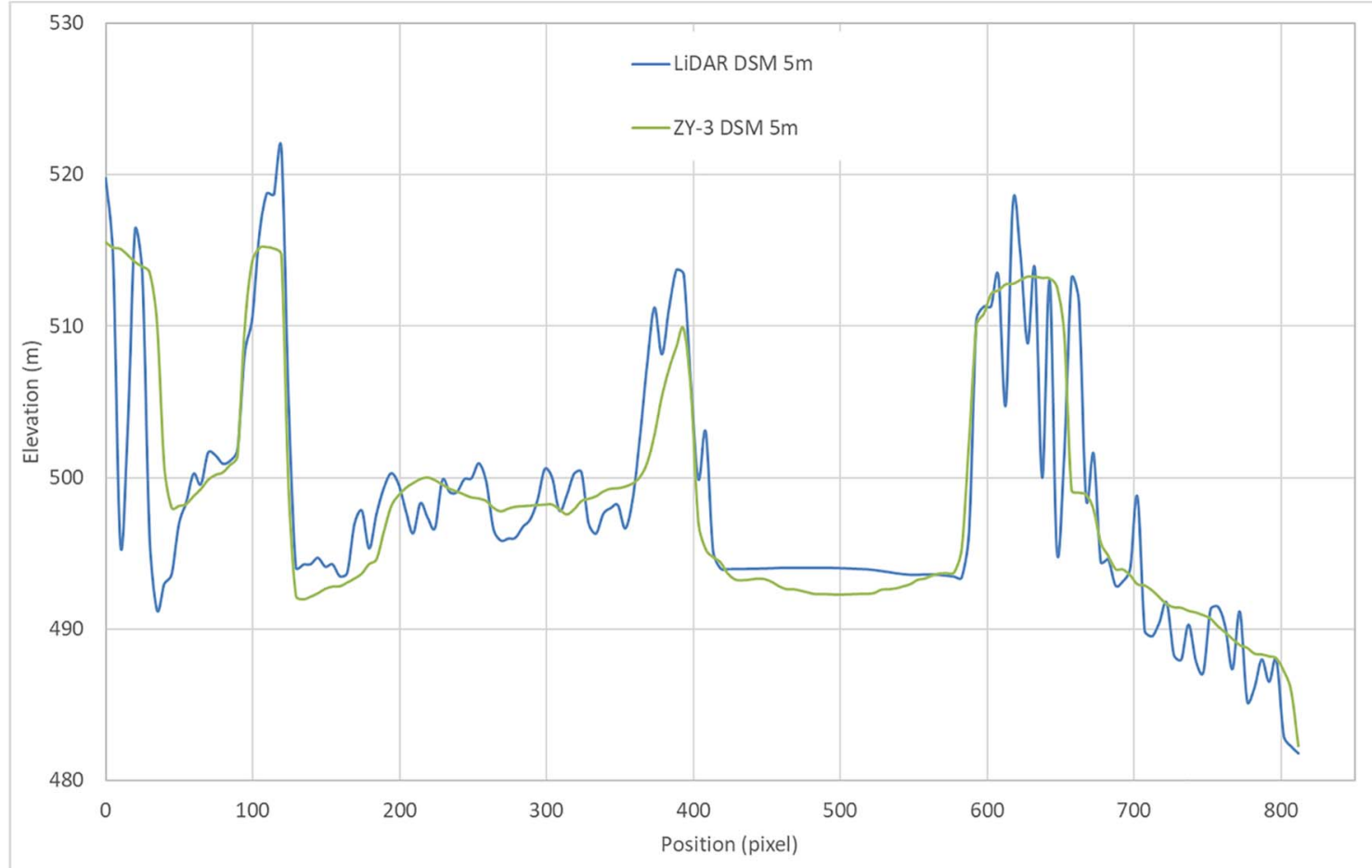

Figure 3 The figure on the left shows a forest profile of different RS systems: (A) colour-infrared (CIR) orthophoto, (B) ZY-3 CHM and (C) LiDAR CHM. The colour scale in (B) and (C) ranges from low heights (green) to very tall heights (red). The right figure (D) presents the DSM cross-section from LiDAR DSM 5 m (blue) and ZY-3 DSM (green) (Geobasisdaten: Bayerische Vermessungsverwaltung).

\section{Volume estimation}

The relative frequency distribution of the estimated timber volume was determined to compare RS-guided sampling with grid sampling. In the first step, we visually compared frequencies
(Figure 8). Both showed a close to normal distributions, with skewness towards the left in grid sampling and towards the right in RS-guided sampling. In the second step, we statistically analysed the similarity of the frequency distributions 


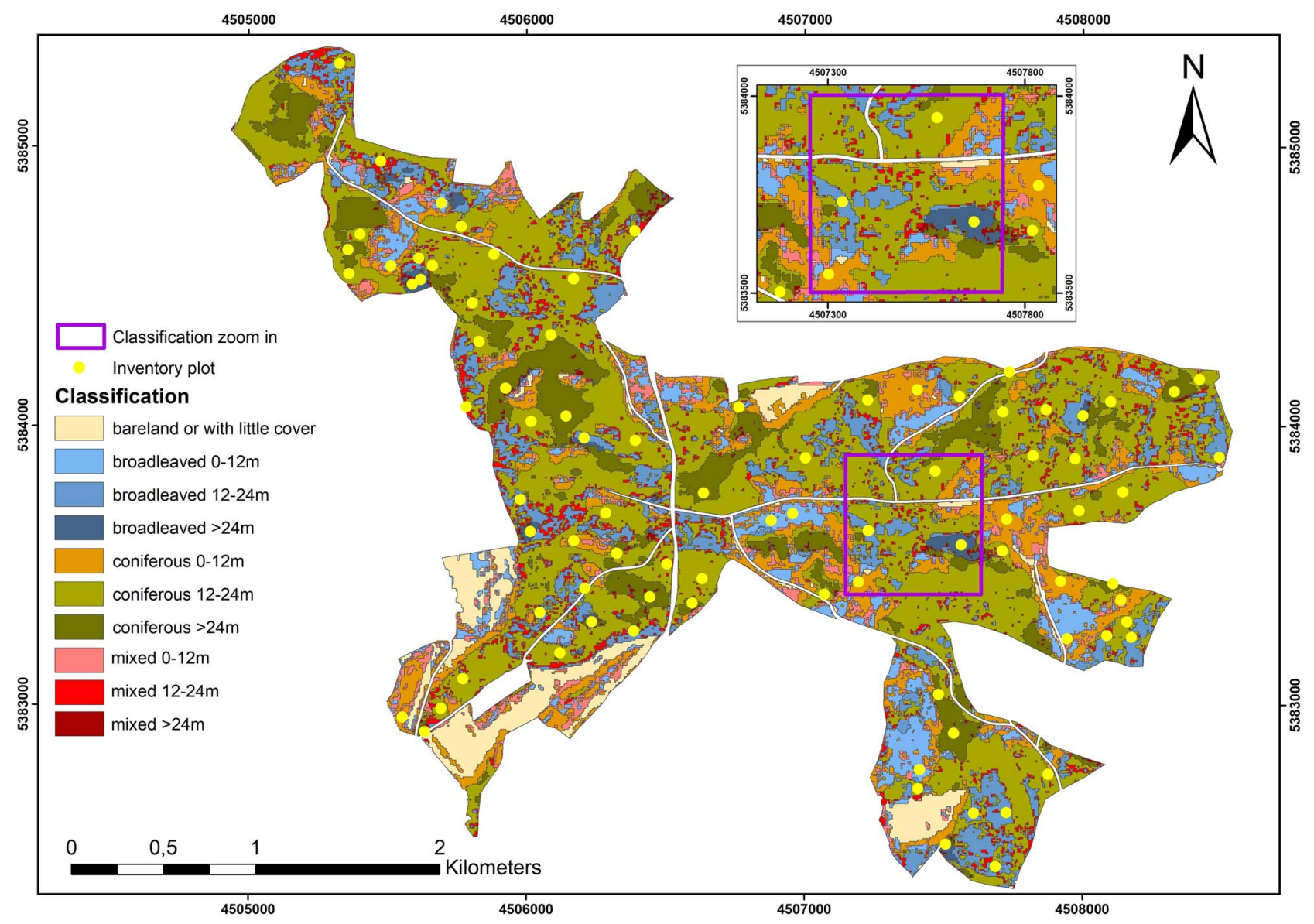

Figure 4 Classification result of ZY-3 data. Illustrated is a map with the three forest types combined with height classes and an additional bare-land class. The locations of the 85 selected inventory plots are also shown. The window on upper right shows an enlarged section of the classification result with inventory plots.

by a chi-square test, which resulted in chi-square $((10)=9.8$, $P=0.46, n=433$ ), suggesting no significant difference between RS-guided sampling and grid sampling. The results of grid sampling calculated with the method of SRS showed a mean timber volume of $336.19 \mathrm{~m}^{3} \mathrm{ha}^{-1}$, a relative standard error of 2.82 per cent and a total timber volume of $117280 \mathrm{~m}^{3}$ (Table 5). The results of the MCS using 85 random plots out of the 348 available grid sample plots for each of the 1000 runs showed a range between 298.89 and $374.05 \mathrm{~m}^{3} \mathrm{ha}^{-1}$ for a 95 per cent confidence interval. The principal results of the MCS were a sample mean of $336.47 \mathrm{~m}^{3} \mathrm{ha}^{-1}$ and a relative standard error of 5.70 per cent (Table 5).

The results for the RS-guided stratification into three foresttype strata (coniferous, broadleaved and mixed) showed a mean timber volume of $381.78 \mathrm{~m}^{3} \mathrm{ha}^{-1}$ compared to a lower mean timber volume of $366.40 \mathrm{~m}^{3} \mathrm{ha}^{-1}$ for six strata. The relative standard error based on three strata was 4.81 per cent and based on six strata 4.75 per cent. Both results were below the targeted 5 per cent error. A comparison between the variances showed a reduction of the variance of 2948 units for six strata. The RE improved from 1.09 for three strata to 1.22 for six strata. This would mean that we would have to increase the MCS standard grid sample density by a factor of 1.09 or 1.22 to achieve the same precision as for three or six strata of the RS-guided sample. The mean timber volume of RS-guided sampling (given six strata) was $30.21 \mathrm{~m}^{3} \mathrm{ha}^{-1}$ (8.99 per cent) higher than the volume estimated by the grid sampling plots. The variances of RSguided sampling based on six strata $\left(25736.61\left[\mathrm{~m}^{3} \mathrm{ha}^{-1}\right]^{2}\right)$ were lower than the variance of grid sampling $\left(31364.21\left[\mathrm{~m}^{3} \mathrm{ha}^{-1}\right]^{2}\right)$. The estimated total timber volume was higher with RS-guided sampling (three and six strata) than with grid sampling.

The calculated difference in mean timber volume of RS-guided sampling with RS height was $-11.32 \mathrm{~m}^{3} \mathrm{ha}^{-1}$ ( -3.37 per cent), which was slightly below the timber volume of the sample mean derived from grid sampling (Table 5). The relative standard error was lower than the desired threshold of 5 per cent. The calculated RE was 1.85 , caused by the low variance of the sample mean.

\section{Discussion}

The objective of our study was to assess the performance of a RS-guided inventory concept based on MS-3D ZY-3 satellite data and compare them with the results of the grid inventory recorded in the same year. The focus was on assessing the accuracy of ZY-3 data products and comparing the results of the RS-guided inventory to the standard grid inventory concerning the forest attributes: height at plot level, tree species composition and timber volume. The results were placed in the context of previously 


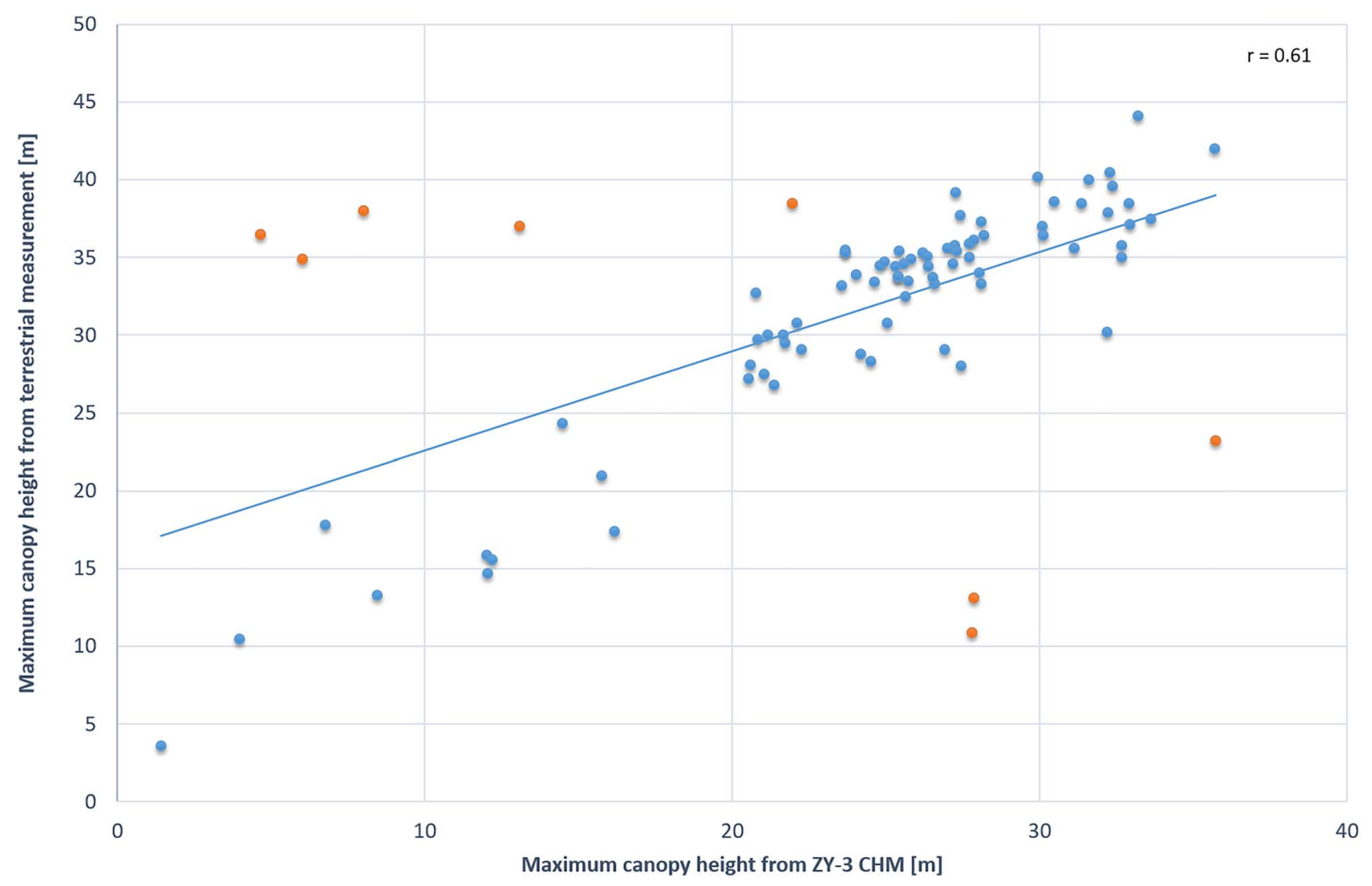

Figure 5 Scatterplot of canopy heights and terrestrially measured canopy heights at inventory plot level. Outliers are shown in orange.

A

- Douglas fir
$\square$ Larch
$\square$ Pine
$\square$ Silver fir
$\square$ Spruce
$\square$ Precious hardwoods
- Other hardwoods
$\square$ Oak
$\square$ Beech

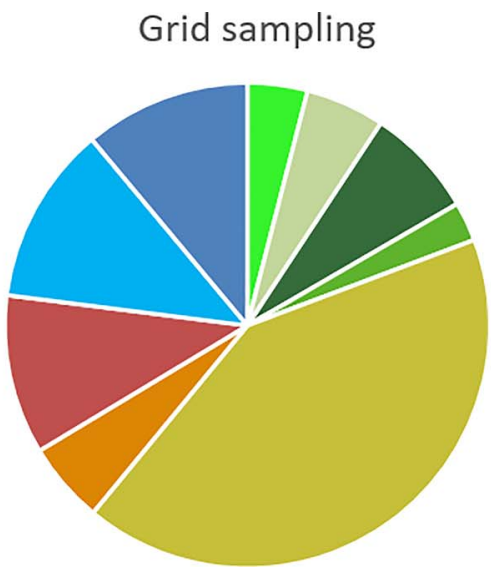

B

- Douglas fir

$\square$ Larch

- Pine

- Silver fir

$\square$ Spruce

- Precious hardwoods

- Other hardwoods

- Oak

घ Beech

RS-guided sampling

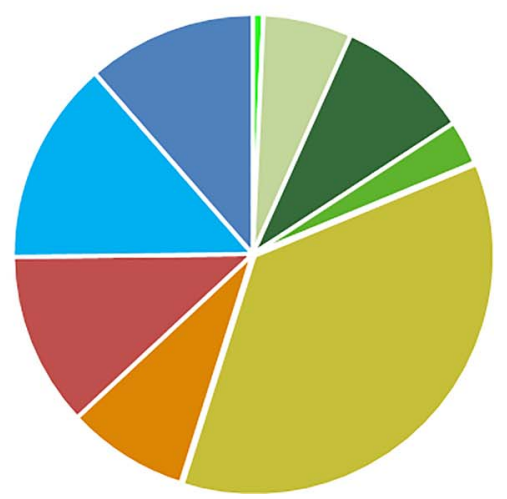

Figure 6 Percentages of tree species $(\geq 7 \mathrm{~cm} \mathrm{DBH}$ ) at forest enterprise level calculated from datasets obtained with permanent grid sampling (A) and RS-guided sampling (B).

published studies with RS data of similar spatial resolution. A summary of the advantages and disadvantages of the RS-guided inventory concept is listed in Table 6.

\section{Accuracy of ZY-3 data products}

The RS-guided forest inventory concept showed promising results, which depend particularly on the quality of the DSM. The ZY-3 DSM was compared with a DSM from LiDAR data. We used LiDAR data as reference, because LiDAR data provide the most accurate forest height information and the highest level of detail (Tian et al. 2017) and is nowadays considered to be an even more reliable source for height information than field data. The visual assessment of the horizontal height profile from a crosssection revealed smoothing and edge effects in ZY-3 DSM. The ZY3 DSM has a spatial resolution of $5 \mathrm{~m}$, for which we expected the mentioned effects. As pointed out in Tian et al. (2017) the quality of DSMs obtained from stereo-satellite data strongly depend 
Table 5 Results for estimating timber volume based on grid and RS-guided sampling.

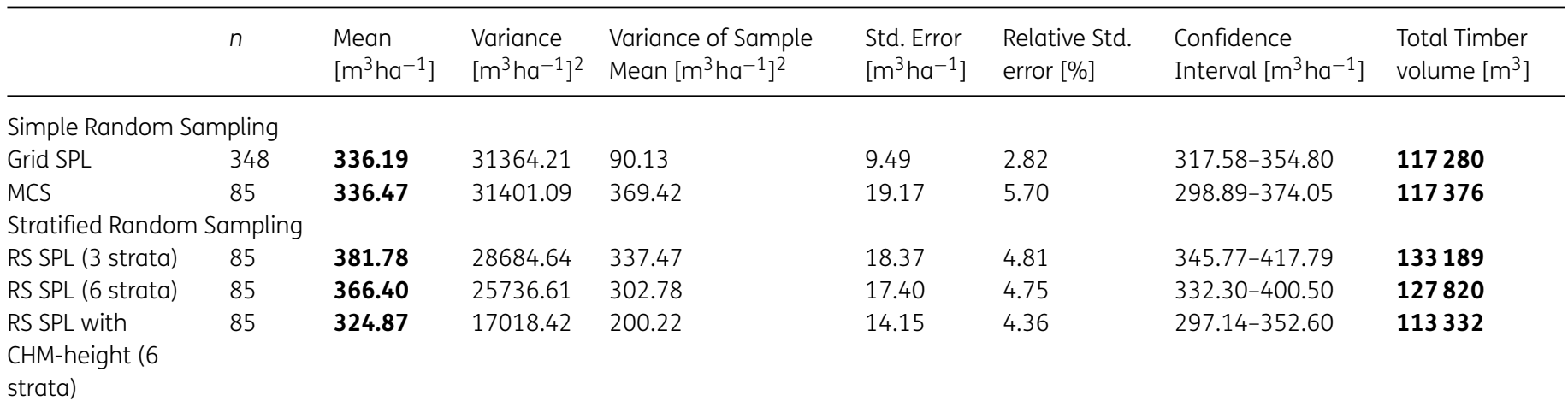

Note: Grid SPL = Grid sampling; MCS = Monte-Carlo Simulation; RS SPL=RS-guided sampling; $n=$ number of inventory plots; $C H M=c r o w n$ height model.

Table 6 Advantages and disadvantages of the RS-guided inventory concept based on height stratification and sample plot selection for operational management

\begin{tabular}{|c|c|}
\hline Advantages & Disadvantages \\
\hline $\begin{array}{l}\text { Stratification of the forest area into similar forest units in the } \\
\text { planning phase. }\end{array}$ & $\begin{array}{l}\text { For subsequent inventories, changes in stratum area are to be } \\
\text { considered. }\end{array}$ \\
\hline Enhanced stratification through canopy height information. & $\begin{array}{l}\text { A remote sensing system with the sensor properties for MS data } \\
\text { and } 3 D \text { capability or data fusion is necessary. }\end{array}$ \\
\hline Reduction of the sample size. & $\begin{array}{l}\text { Due to temporary sampling, no recording of the increment is } \\
\text { possible. }\end{array}$ \\
\hline $\begin{array}{l}\text { Approach for heterogeneous mixed forests with high structural } \\
\text { richness. }\end{array}$ & $\begin{array}{l}\text { To reduce errors, the remote sensing data and terrestrial surveys } \\
\text { should be conducted in a timely manner. }\end{array}$ \\
\hline
\end{tabular}

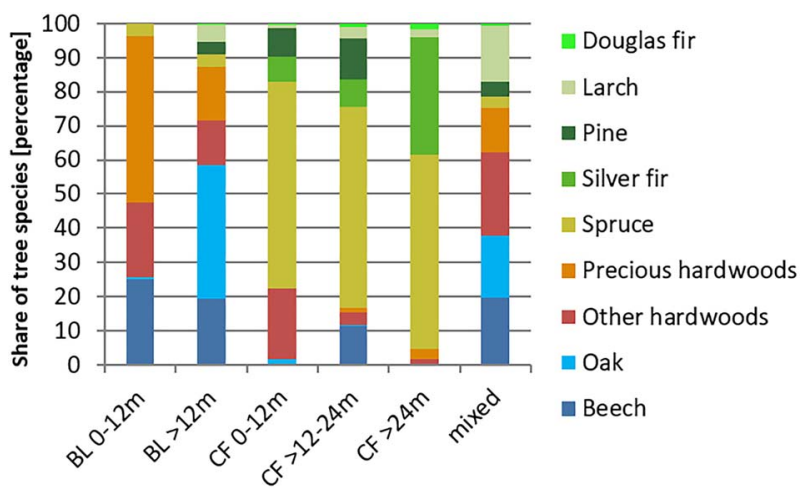

Figure 7 The tree species ( $\geq 7 \mathrm{~cm} \mathrm{DBH}$ ) composition of the RS-guided sampling is displayed in percentage for each stratum: broadleaved (BL), coniferous (CF) and mixed.

on the spatial resolution of the satellite system. The quality of DSMs also depends on the applied dense matching approaches, which have recently been improved for stereo sensors with a lower resolution (Reinartz et al. 2014). Han et al. (2020) compared the performance of image matchers of five different software packages in a study with WorldView-1 stereo data

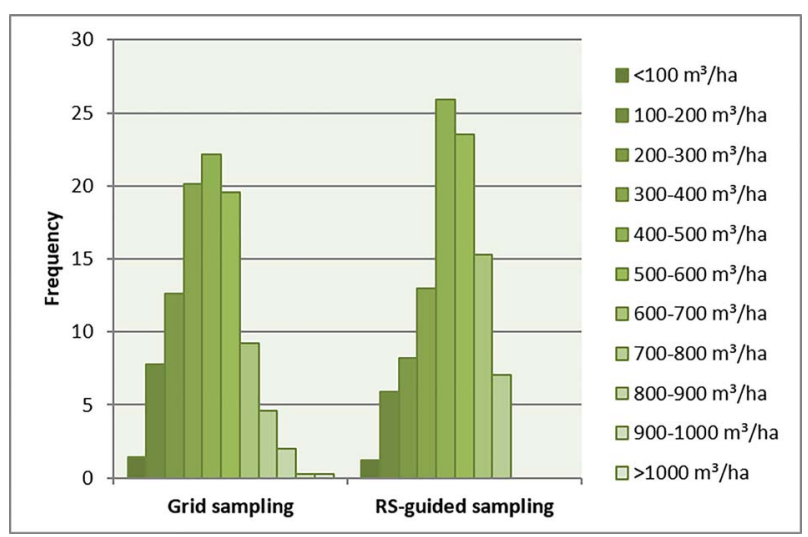

Figure 8 Relative frequency distribution of timber volume (in cubic metres per hectare of timber harvested with bark). Distributions based on permanent grid sampling (left) and RS-guided sampling with terrestrial height measurement (right) are shown.

(spatial resolution $0.5 \mathrm{~m}$ ). The results showed notable differences even using the same algorithms implemented in the different software packages. Therefore, our approach could be further 
tested by generating a DSM with a different software package and, if available, with ground control points (GCPs) to further improve the quality of the DSM for forestry applications. Due to the heterogeneity of our forest area, which is characterized by forest gaps, a variety of development stages, diverse tree species compositions, etc., testing of the DSMs accuracy for different land-cover types is necessary (Tian 2013a; Tian et al. 2017). We performed an accuracy assessment of the height values over five land-cover types of the ZY-3 DSM, which showed a generally good performance. Our results are in line with Tian (2013a), reporting similar results for a forest in southern Germany, using DSM data from WorldView-2 (spatial resolution $1 \mathrm{~m}$ ) and Cartosat1 (spatial resolution $5 \mathrm{~m}$ ). A NMAD between $3.95 \mathrm{~m}$ and $8.82 \mathrm{~m}$ as well as a STD between $6.46 \mathrm{~m}$ and $12.21 \mathrm{~m}$ was observed for forested areas. As already mentioned, LiDAR data have a high degree of detail and are a recognized reference for forest height information in scientific studies. Nevertheless, the LiDAR data of this study should be viewed critically regarding the time of recording in early spring when the forest was in a leaf-off stage or at least only partially in leaf. Since we obtained the data from the LDBV, we had no influence on the time of recording. This and the time-offset between the collection of the data from which the ZY-3 DSM and LiDAR DSM were derived may explain parts of the observed height differences between the two DSMs. Certainly, the correlation could be improved if the data capture would be conducted in the same year.

The classification of the forest-type classes based on MS and angular information derived from the ZY-3 dataset is in line with the results of the classification approach of Wallner et al. (2018). The latter study obtained an OA of 84 per cent for coniferous and broadleaved forest types in Southeast Germany, using RapidEye data with a similar spatial resolution of $5 \mathrm{~m}$. Also based on RapidEye data, Schneider et al. (2013) obtained an OA range between 66 per cent and 77 per cent for classifying a forest in southern Bavaria into coniferous, broadleaved and mixed forest types using a multi-temporal data stack. The present results are also in line with the study of Ottosen et al. (2020). They used different tiles of mono-temporal Sentinel-2 data with a spatial resolution of $10 \mathrm{~m}$ in the Midlands (England) to classify no trees, broadleaved trees and coniferous trees with OA ranging from 83.43 per cent to 89.97 per cent.

\section{Forest attributes}

The comparison of canopy heights from ZY-3 CHM data compared with the terrestrial height measurements at plot level was affected by a time difference of 4 years. Therefore, we corrected the maximum canopy height at plot level obtained from the $Z Y-3$ CHM with a tree species-specific PAI. This is a common approach to compensate for the temporal difference of RS datasets and has for example been applied in the studies of Stepper et al. (2015) and Tian et al. (2017). The comparison of maximum height at plot level showed a Pearson's correlation $r$ of 0.61 . The result is in line with the study of Ginzler and Hobi (2015) who reported Pearson's correlations ranging from 0.64 to 0.91 when comparing tree heights from CHM with terrestrially measured tree height from NFI sample plots. Due to the time difference between the data sets, some forest management measures may have changed the strata boundary. However, based on the above comparison, only minor changes within the strata could be detected. In our dataset, we identified eight sample plots as outliers. We assumed removal of trees during forest operations in plots with low terrestrial measured height and high values in ZY-3 CHM. Records taken by forest managers in the study region revealed a bark beetle attack on tall trees during the time gap between acquisition of RS and field data, which confirmed this assumption. The inventory plots showing tall trees measured in the field but low heights in the ZY-3 CHM may be due to the smoothing effect of the $\mathrm{CHM}$, which leads to a systematic underestimation of tree heights. This outcome is further aggravated by the fact that terrestrial tree heights at plot level were only measured for trees with a high $\mathrm{DBH}$, as shown by the outliers identified. For future studies, attention should therefore be paid to a smaller temporal difference between the RS data and the terrestrial survey.

Tree species composition of common species were well covered at plot level. The RS-based stratification approach led to an approximately equal distribution of coniferous and broadleaved tree species for the plots inventoried according to the RS-guided sampling compared to grid sampling. The only critical tree species were Douglas fir and oak. According to forest management records, these species were planted in small groups to close gaps caused by bark beetles. Even when correctly classified, these objects did not fulfil the condition of an area of $500 \mathrm{~m}^{2}$ required to be qualified as a sample plot and may therefore be underrepresented in our candidate polygons in the RS-guided approach.

The estimated timber volume and the relative standard error of timber volume was used as a measure of accuracy to compare different sampling schemes following Cochran (1977). The results of the RS-guided sampling showed that the threshold of $\leq 5$ per cent could be met for all examined stratification levels. To identify differences between the two sampling methods, the relative frequency distribution of timber volume was analysed statistically and visually. The statistical analysis revealed no significant differences between the frequency distributions of the sampling methods. The visual interpretation showed a similar pattern. However, in the RS-guided sampling, certain areas were recorded with low frequency or were not recorded, such as areas with very low timber volume $\left(200-300 \mathrm{~m}^{3} \mathrm{ha}^{-1}\right)$ and areas with very high timber volume (above $900 \mathrm{~m}^{3} \mathrm{ha}^{-1}$ ). This could be caused by the distribution of sampling plots to the respective strata. The influence of the stratification approach was examined based on the RE. Stratification into three strata showed a lower RE than into six strata. McRoberts et al. (2002) obtained similar RE values for total volume (1.25 to 1.75) when using Landsat TM imagery and ancillary data to divide their test site into four strata. Further, the result of estimated timber volume of the RSguided sampling with RS height was closer to the grid sampling values used as reference than the RS-guided sampling. The small difference in the values could be due to the height information derived from the CHM. For this approach, only the maximum height information from the CHM at the inventory plots were used for timber volume estimation.

An important factor in inventory costs is the sample size. As Næsset (1997) stated, the collection of data across a regular grid is time consuming, and the costs are proportional to the number of sample plots. The stratification approach into height 
classes allowed the reduction of inventory plots by about 75 per cent, which leads to lower inventory costs. Procurement and evaluation costs of the RS data must be considered but are likely to be lower than field inventory costs, once functional and streamlined workflows are implemented.

\section{Conclusion}

The study demonstrates that the use of high-resolution MS3D RS data can add value to the planning and implementation of local forest inventories. The suggested approach of exploiting forest height information from stereo-satellite data for prestratification of the forest area in a local forest inventory system allowed to reduce the sample size by 75 per cent without significant drop in accuracy for the targeted forest inventory parameters as compared to the full grid inventory. Contrarily, a random reduction of the samples by 75 per cent led to significantly worse results as demonstrated with our MCS. The presented approach could be further refined by improving the quality of the applied data products and the acquisition timing. Problems related to the time gap between field and RS data collections could be partly resolved here by correcting the field data with PAI models but changes caused by management activities also occurred and could not fully be accounted for. Nevertheless, it was possible to use the derived height information from $\mathrm{ZY}$ 3 DSM for volume calculations and the results matched the required relative standard error of $\leq 5$ per cent. Consequently, the suggested approach allows either a reduction of inventory costs or alternatively a higher frequency of inventories. The latter may become necessary to adequately capture changes in the forests related to the expected increased frequency and magnitude of biotic and abiotic calamities in forests in the future.

\section{Authors' contributions}

Adelheid Wallner is the lead author. She performed the analyses and wrote the manuscript. Thomas Schneider proposed the overall concept of the study. Alata Elatawneh, Thomas Schneider and Adelheid Wallner (Wallner et al. 2018) developed the sampling design. Stefan Friedrich provided statistical support and analysed part of the inventory data. Emanuel Geier and Christoph Meder-Hokamp did the fieldwork. Remotely sensed data processing was done by Zilin Wei, Mengistie Kindu and Jiaojiao Tian. Martin Döllerer did LiDAR data preparation. The framework of the manuscript and detailed edits were the work of Adelheid Wallner and Thomas Schneider. Thomas Knoke provided research coordination, statistical support and forest expertise to the paper.

\section{Data availability}

Data available on request. The data underlying this article will be shared on reasonable request to the corresponding author.

\section{Acknowledgements}

The authors thank the Land Satellite Remote Sensing Application Center, Ministry of Natural Resources of the People's Republic of China and the
DLR for the provision of ZY-3 data, and for their excellent support. Special thanks go to the team of the conventional permanent grid inventory used as a reference. Additionally, the authors grateful to Karen Grosskreutz, Allyson Cappello and Alena Chilian for the language editing of the manuscript. We also express appreciation to the anonymous reviewers for their valuable comments. Their contribution improved the quality of the manuscript.

\section{Conflict of interest statement}

None declared.

\section{Funding}

This research received no external funding.

\section{References}

Baatz, M., Benz, U., Dehghani, S., Heynen, M., Höltje, A., Hofmann, P. et al. 2004 eCognition User Guide. Definiens Imaging GmbH, Munich, Germany. Blaschke, T 2010 Object based image analysis for remote sensing. ISPRS 65, 2-16, http://doi.org/10.1016/j.isprsjprs.2009.06.004.

Buchhorn, M., Schneider, T. 2010a Synergistic Use of Spectral and Angular Signatures from Proba/CHRIS Hyperspectral Images in a Temporal Context. In Imagin [e.g] Europe: Proceedings of the 29th Symposium of the EARSeL. Manakos, I. and Kalaitzidis, C. (eds). IOS Press, Amsterdam, pp. 18-25. http://doi.org/10.3233/978-1-60750-494-8-18.

Buchhorn, M., Schneider, T. 2010b Improving hyperspectral, multidirectional analysis of Proba/Chris observations by angular signatures from the same data set. In Proceedings of the Hyperspectral Workshop 2010. 17 19 March 2010; ESRIN, Frascati, Italy, ESA SP.

Cochran, W. 1977 Sampling Techniques. John Wiley \& Sons, New York, USA.

Congalton, R.G. 1991 A review of assessing the accuracy of classifications of remotely sensed data. Remote Sens. Environ., 37, 35-46, https://doi.o rg/10.1016/0034-4257(91)90048-B.

Dahm, S. 2006 Auswertungsalgorithmen für die zweite Bundeswaldinventur. Bundesforschungsanstalt für Forst - und Holzwirtschaft. Institut für Waldökologie und Waldinventuren, Eberswalde, Germany, 43 pp.

D’Angelo, P., Lehner, M., Krauss, T., Hoja, D. and Reinartz, P. 2008 Towards automated DEM generation from high resolution stereo satellite images. Int. Soc. Photogramm. Remote Sens. 37, 1137-1342.

D'Angelo, P. 2013 Evaluation of ZY-3 for DSM and ortho image generation. ISPRS, XL-1/W1, pp. 57-61, https://doi.org/10.5194/isprsarchives-XL-1W1-57-2013.

Dekok, R., Schneider, T., Ammer, U. 1999 Object based classification and applications in the Alpine forest environment. International Archives of Photogrammetry and Remote Sensing, 32, 3-4.

Fang, S. and Chen, Y. 2012 Sensor calibration of three-line CCD scanners on - 3. ISPRS, XXXIX-B1 109-114 https://doi.org/10.5194/isprsarchivesXXXIX-B1-109-2012.

Fassnacht, F.E., Mangold, D., Schäfer, J., Immitzer, M., Kattenborn, T., Koch, B., Latifi, H. 2017 Estimating stand density, biomass and tree species from very high resolution stereo-imagery - towards an all-in-one sensor for forestry applications? Forestry 90, 613-631, https://doi.org/10.1093/ forestry/cpx014.

Friedrich, S., Döllerer, M. and Knoke, T. 2017 Permanente Stichprobeninventur im Universitätswald der TUM. Allgemeine Forst Zeitschrift für Waldwirtschaft und Umweltvorsorge 72, 13-14.

Gautam, B.R., Tokola, T., Hamalainen, J., Gunia, M., Peuhkurinen, J., Parviainen, H., Leppanen, V., Kauranne, T., Havia, J., Norjamaki, I. 
Sah, B.P. 2010 Integration of airborne LiDAR, satellite imagery, and field measurements using a two-phase sampling method for forest biomass estimation in tropical forests. Presented at International Symp. "Benefiting from Earth Observation", 4-6 October, Kathmandu, Nepal, p. 7.

Ginzler, C. and Hobi, M. 2015 Countrywide stereo-image matching for updating digital surface models in the framework of the Swiss National Forest Inventory. Remote Sens. 7, 4343-4370, https://doi.org/10.3390/ rs70404343.

Grafström, A., Schelin, L. 2014 How to select representative samples. Scand. J. Stat. 41, 277-290, https://doi.org/10.1111/sjos.12016.

Han, Y., Qin, R., Huang, X. 2020 Assessment of dense image matchers for digital surface model generation using airborne and spaceborne images - an update. Photogramm. Rec. 35, 58-80. https://doi.org/10.1111/pho r.12310.

Hawbaker, T.J., Keuler, N.S.L., Adrian, A., Gobakken, T., Contrucci, K., Radeloff, V.C. 2009 Improved estimates of forest vegetation structure and biomass with a LiDAR-optimized sampling design. J. Geophys. Res. 114, https://doi.org/10.1029/2008JG000870.

Hirschmüller, H. 2008 Stereo processing by semiglobal matching and mutual information. IEEE Trans. Pat. Ana. Ma. Int. 30, 328-341, https:// doi.org/10.1109/TPAMI.2007.1166.

Höhle, J. and Höhle, M. 2009 Accuracy assessment of digital elevation models by means of robust statistical methods. ISPRS J. Photogramm. Remote Sens. 64, 398-406, https://doi.org/10.1016/j.i sprsjprs.2009.02.003.

Höhle, J. and Potuckova, M. 2011 Assessment of the Quality of Digital Terrain Models. European Spatial Data Research, EuroSDR, http://www.eu rosdr.net/publications/60.pdf.

Immitzer, M., Stepper, C., Böck, S., Straub, C., Atzberger, C. 2016 Use of WorldView-2 stereo imagery and National Forest Inventory data for wallto-wall mapping of growing stock. For. Ecol. Manag. 359, 232-246, https:// doi.org/10.1016/j.foreco.2015.10.018.

IPCC 2018 Global Warming of $1.5^{\circ} \mathrm{C}$. An IPCC Special Report on the impacts of global warming of $1.5^{\circ} \mathrm{C}$ above pre-industrial levels and related global greenhouse gas emission pathways, in the context of strengthening the global response to the threat of climate change, sustainable development, and efforts to eradicate poverty. Masson-Delmotte, V., Zhai, P., Pörtner, H.-O., Roberts, D., Skea, J., Shukla, P.R., Pirani, A., Moufouma-Okia, W., Péan, C., Pidcock, R., Connors, S., Matthews, J.B.R., Chen, Y., Zhou, X., Gomis, M.I., Lonnoy, E., Maycock, T., Tignor, M., and Waterfield T. (eds). ISBN-978-92-9169-151-7.

Johann, K. 1990 Adjustierung von Bestandeshöhenkurvenscharen nach der Methode des Koeffizientenausgleichs. Meth Proposal Working Group "Auswertemethodik bei langfristigen Versuchen". Sek. Ertragskd. Dt. Verb. Forstl. Forschungsanstalten, München.

Kennel, E. 1973 Bayerische Waldinventur 1970/71. Inventurabschnitt I: Großrauminventur Aufnahme- und Auswertungsverfahren. Forstl. Forsch. Anst. Münch. Forschungsberichte 12.

Köhl, M., Magnussen, S., Marchetti, M. 2006 Sampling Methods, Remote Sensing and GIS Multiresource Forest Inventory. Tropical Forestry (pp. 373). Berlin: London: Springer, ISBN 978-3-540-32571-0, https://doi.org/10.1007/978-3-540-32572-7.

Knoke, T. and Weber, M. 2006 Expanding carbon stocks in existing forests - a methodological approach for cost appraisal on the enterprise level. Mitigation Adapt. Strateg. Glob. Chang. 11, 579-605.

Knoke, T., Schneider, T., Hahn, A., Griess, C., Rößiger, J. 2012 Forstbetriebsplanung. 1st edn. Ulmer: Stuttgart, ISBN 978-3-8001-9243-4.

Li, S., Liu, Q., Wang, N., Li, Z., Chen, E., Pang, Y. et al. 2019 Forest stand height estimation using Ziyuan-3 tri-stereo imagery and Lidar. IGARSS 2019 IEEE https://doi.org/10.1109/IGARSS.2019.8897913.
Li, G., Xie, Z., Jiang, X., Lu, D., Chen, E. 2019 Integration of ZiYuan-3 multispectral and stereo data for modeling aboveground biomass of larch plantations in North China. Remote Sens. 11, 2328, https://doi.o rg/10.3390/rs11192328.

Massey, A., Mandallaz, D., Lanz, A. 2014 Integrating remote sensing and past inventory data under the new annual design of the Swiss National Forest Inventory using three-phase design-based regression estimation. Can. J. For. Res. 44, 1177-1186.

McRoberts, R.E., Nelson, M.D., Wendt, D.G. 2002 Stratified estimation of forest area using satellite imagery, inventory data, and the k-nearest neighbour technique. Remote Sens. Environ. 82, 457-468, https://doi.o rg/10.1016/S0034-4257(02)00064-0.

Mosandl, R. and Paulus, F. 2002 Rationelle Pflege junger Eichenbestände. Allg. Forst Z. Waldwirtschaft 11, 581-584.

Mosandl, R. and Höllerl, S. 2013 Der Universitätswald der LudwigMaximilians-Universität München: Verbindung von Waldbautheorie und -praxis. Allg. Forst- Jagdztg 9, 22-24.

Müller-Starck, G., Friedrich, S., Knoke, T. 2019 The Forest of the LudwigMaximilians-Universität München. SILVA Network Conference, Faculty of Forestry and Wood Sciences. Czech University of Life Sciences, Prague, pp. 9-16.

Næsset, E. 1997 Determination of mean tree height of forest stands using airborne laser scanner data. ISPRS 52, 49-56. https://doi.org/10.1016/ S0924-2716(97)83000-6.

Ottosen, T.-B., Petch, G, Hanson, M, Skjøth, C.A. 2020 Tree cover mapping based on Sentinel-2 images demonstrate high thematic accuracy in Europe, Int. J. Appl. Earth Obs. Geoinf. 84, https://doi.org/10.1016/j.ja g.2019.101947.

Pulkkinen, M., Ginzler, C., Traub, B., Lanz, A. 2018 Stereo-imagery-based post-stratification by regression-tree modelling in Swiss National Forest Inventory. Remote Sens. Environ. 213, 182-194, https://doi.org/10.1016/ j.rse.2018.04.052.

Reinartz, P., Tian, J., Arefi, H., Krauss, T., Kuschk, G., Partovi, T., d’Angelo, P. 2014 Advances in DSM generation and higher level information extraction from high resolution optical stereo satellite data. In Proceedings of the 34th Earsel Symposium. Zagajewski, B., Kycko, M. and Reiter, R. (eds). Warsaw, Poland, 16-20 June; pp. 8.33-8.36.

Rouse, J.W., Haas, R.H., Schell, J.A. and Deering, D.W. 1974 Monitoring vegetation systems in the Great Plains with ERTS. In Proceedings of the ERTS-1 3rd Symposium, Vol. 1. NASA SP-351. NASA, Washington, pp. 309317.

Schneider, T. 2009 Investigations toward the extraction of angular signatures from ALOS/PRISM datasets. In Proceedings of ALOS PI 2008 Symposium. Lacoste, H. and Ouwehand, L. (eds). ESTEC: Noordwijk, Netherlands.

Schneider, T., Elatawneh, A., Rahlf, J., Kindu, M., Rappl, A., Thiele, A., Hinz, S. 2013 Parameter Determination by RapidEye and TerraSAR-X Data: A Step toward a Remote Sensing Based Inventory, Monitoring and Fast Reaction System on Forest Enterprise Level. In EOGC, Krisp, J.M., Meng, L., Pail, R., Stilla, U. (eds.) Springer: Berlin, Heidelberg, Germany, pp. 81-107.

Shiver, B. and Borders, B. 1996 Sampling Techniques for Forest Resource Inventory. John Wiley \& Sons, INC, New York, Chichester, Brisbane, Toronto, Singapore, ISBN 978-0-471-10940-2.

Straub, C., Tian, J., Seitz, R., Reinartz, P. 2013 Assessment of Cartosat1 and WorldView-2 stereo imagery in combination with a LiDAR-DTM for timber volume estimation in a highly structured forest in Germany. Forestry 86, 463-473, https://doi.org/10.1093/forestry/cpt017.

Stepper, C., Straub, C., Pretzsch, H. 2015 Assessing height changes in a highly structured forest using regularly acquired aerial image data. Forestry 88, 404-316, https://doi.org/10.1093/forestry/cpu050. 
Tang, X. and Xie, J. 2012 Overview of the key technologies for highresolution satellite mapping. Int. J. Dig. Earth 5, 228-240. https://doi.o rg/10.1080/17538947.2011.647775.

Tian, J. 2013a 3D Change Detection from High and Very High-Resolution Satellite Stereo Imagery. Universität Osnabrück, Dissertation.

Tian, J., Reinartz, P., d'Angelo, P., Ehlers, M. 2013b Region-based automatic building and forest change detection on Cartosat-1 stereo imagery. ISPRS 79, 226-239, https://doi.org/10.1016/j.isprsjprs.2013.02.017.

Tian, J., Schneider, T., Straub, C., Kugler, F., Reinartz, P. 2017 Exploring digital surface models from nine different sensors for forest monitoring and change detection. Remote Sens. 9, 287, https://doi.org/10.3390/ rs9030287.

Trimble 2013 eCognition Developer 8.9 Reference Book. 8.9.1 edn. Trimble Germany GmbH, München, p. 249.

Tomppo, E. 2006 The Finnish National Forest Inventory. In Proceedings of the Eighth Annual Forest Inventory and Analysis Symposium. McRoberts,
R.E., Reams, G., Van Deusen, P.C., McWilliams, W.H. (eds). Monterey, CA. Gen. Tech. Report WO-79, Washington, DC: U.S. Department of Agriculture, Forest Service. 39-46, https://doi.org/10.1007/1-4020-4381-3_11.

Walentowski, H., Gulder, H.J., Kölling, C., Ewald, J., Türk, W. 2001 Die Regionale natürliche Waldzusammensetzung Bayerns. Bayerische Landesanstalt für Wald und Forstwirtschaft No. 32, Freising, p. 99.

Wallner, A., Elatawneh, A., Schneider, T., Kindu, M., Ossig, B., Knoke, T. 2018 Remotely sensed data controlled forest inventory concept. Eur. J. Remote Sens. 51, 75-87, https://doi.o rg/10.1080/22797254.2017.1403295.

Wei, Z. 2018 Forest Type Classification Options Exploring Remote Sensed Data from the ZiYuan-3 Satellite System. Master Thesis of the Technical University of Munich, Freising.

Xie, Z., Chen, Y., Lu, D., Li, G. 2019 Classification of land cover, Forest, and tree species classes with ZiYuan-3 multispectral and stereo data. Remote Sens. 11, 164, https://doi.org/10.3390/rs11020164. 